\title{
Keele on race equality
}

\section{Shane O’Neil ${ }^{1}$}

The shocking killing of George Floyd in police custody in Minneapolis has inevitably led to protests around the world in support of Black Lives Matter. We hope that this represents a long overdue turning point and that demands for an end to racial injustice are heard and acted on everywhere. These protests have highlighted once again the fact that sustained and systemic racism is one of the greatest challenges facing humanity today. Race-based inequality pervades almost every aspect of our lives and so our efforts to fight it in society have to be fit for purpose in tackling this enormous challenge.

This problem has deep historical roots, in the process of racialized colonialism that characterized much of global history in the modern era, in the slave trade and other exploitative, abhorrent and brutal practices associated with colonialism. We have seen in recent days how the historical legacy of slavery and colonialism remains present in our cities and on our streets in the memorialization of figures directly responsible for these practices. We know too that this legacy persists in the racially differentiated lived experience of people in this country and in other Western societies. Racism is pervasive, structural and systemic in that people of color face additional risks in their daily lives, of being abused, stopped by the police or subject to microaggressions suggesting they don't fully belong in our institutions and in our society. Not having to even think about such risks is precisely what White privilege entails. These differences in lived experience are grounded in a deep structure of racebased inequality. This is clear for all to see in social scientific evidence that tracks inequalities in relation to wealth, opportunity, health (including the impact of Covid-19), education, criminal justice and many of the other benefits and burdens of social co-operation.

As a university committed to social progress and founded on a vision that demands we strive to use knowledge to make a positive difference for the communities we serve, we at Keele have to embrace our moral obligation to be leaders in the struggle against racism. It is not enough to be non-racist, to try to eliminate racism from our community and campus. We are an integral part of a wider society, locally, nationally and globally, that is systemically racist. So, if we want to do something positive about it, being neutral and non-racist, trying not to exacerbate or perpetuate racial injustice is not going to be effective. We must become an anti-racist institution, one that makes a full contribution to the struggle against the pandemic of racism that has infected our societies for centuries.

We have made strides in recent years to become an anti-racist institution. While our commitment to the Race Equality Charter is a very useful framework for us to use in galvanizing our efforts, we know that this is not enough in itself. That framework has allowed us to measure some of the ways in which our institution reflects the race-based inequalities that scar our societies. We know, for example, that our BAME students are less likely to be taught by academic staff who share their life experiences, and less likely to achieve a higher class of degree than non-BAME students. In our submission for a Bronze Award for the Race Equality Charter we carefully analysed our data and put in place ambitious staff- and student-focused action plans. Having been successful with that submission, we are now in the process of implementing those plans, and some of the key actions are highlighted later in this statement.

From the outset, we were aware of the fact that signing up to the Race Equality Charter, analysing data and creating action plans, were never in themselves going to turn 
us into an anti-racist institution. In order to address the structural and cultural roots of this problem, we need to engage in a radically transformative process that changes the way we think about differences based on race and ethnicity. We cannot just make gestures of inclusion or speak about the benefits of diversity, we also need to take measures that will further the demand for equality. A good start would be to try to ensure that all staff and students feel equally safe on campus. Safety is not as high an ideal as justice so this should be a minimal standard that we seek to achieve. Yet, we know that if we consider safety in the deepest sense of that word, we are not all equally safe. BAME staff and students are more likely to be subjected to prejudice and discrimination, more likely to be made to feel unwelcome by unhelpful questions or remarks about their identities, and more likely to study a course that does not reflect adequately on the experience and achievements of people of a similar background.

Being sincere is not enough. We have to be effective and this will require an allinstitution effort involving all staff and all students. Here are some of the key projects we are taking forward in order to further the process of Keele becoming an anti-racist institution. These are important immediate steps on this critically important journey. Please reflect on what you can do to ensure that we succeed in taking these next steps.

- We have underway an institution-wide process to decolonize our curriculum. Every subject group in the institution is to assess critically the content and mode of delivery of its curriculum so as to ensure that it is maximally inclusive of all and reflective of the diversity of identities represented in our community.

- We have established new organizational structures to support our Access and Participation Plan, with a specific focus on the awarding gap between BAME and non-BAME, and more specifically Black and White students. Each school will need to report on progress against targets aimed at closing these gaps.

- We are committed to developing educational and cultural resources that support anti-racist work across campus, following on from an initial video that was made on the microaggressions experienced by our BAME students.

- We are collaborating with the Decolonise Keele Network, the SU and the KPA to address other student-related race equality issues, including a relaunch on the Never OK campaign that makes explicit a zero tolerance towards racism.

- We are working with the BAME Staff Network to implement a new phase of our Race Equality Mentoring programme and to introduce a new BAME Allies programme.

- We are implementing new anti-bullying and harassment procedures, including an anonymous reporting tool.

- We are developing online resources and materials for staff training on race equality.

- We are investing in the Race Equality Lecture Series and other public events related to the struggle against racism.

Through all of these projects, we hope to open up new opportunities for our BAME students and staff to speak about their experiences, to be heard and to shape this process of change. But the responsibility for driving change falls on all of us. We call on every member of the Keele community to reflect critically on the question as to what more each of us can do as individuals to be effective in the struggle against racism. This must go beyond being nonracist. If we are to eliminate racism from our community, we need to acknowledge the depth of its roots, its pervasiveness and systematic nature. That requires us to be actively anti-racist, ready to analyse forensically its impact on all of our interactions and practices. We are committed to taking bold and sustained action so that we can live up to our vision and offer leadership in society for the ongoing struggle against racial injustice. 
Journal of Global Faultlines, 2020

Vol. 7, No. 1, 111-113.

\section{Note}

${ }^{1}$ Professor of Political Theory, Co-Chair of the Race Equality Charter Self-Assessment Team, and Pro ViceChancellor for Advancement \& Global Engagement, Executive Dean of the Faculty of Humanities \& Social Sciences, Keele University. 